\title{
ANALISIS MINERAL PEMBENTUK FACIES GUA SALUKANG KALLANG KAWASAN KARST TAMAN NASIONAL BANTIMURUNG BULUSARAUNG MAROS
}

\author{
${ }^{1)}$ Rati Puspita Sari, ${ }^{2)}$ Muhammad Arsyad, ${ }^{3)}$ Vistarani Arini Tiwow \\ Universitas Negeri Makassar \\ Kampus UNM Parangtambung Jln. Daeng Tata Raya, Makassar, 90224 \\ 1)e-mail : ratipuspita73@gmail.com
}

\begin{abstract}
Analysis Mineral Forming Facies Cave Salukang Kallang Karst Area National Park Bantimurung Bulusaraung Maros. Research has been done for the purpose of describing the characteristics of the Kallang Salukang Cave and analyzing the mineral content of cave caridoid that include a sample of cave ornaments such as stalactites, stalactites, lime, sand and soil done in Laboratory of Microstructure of FMIPA UNM using X-Ray Diffraction (XRD) method. From the results of the research in which the characteristics of the Salukang Kallang Cave can be found flora, fauna, and is a cave that is still active characterized by the presence of water seepage in cave ornaments and the existence of a low-temperature underground river that is $26^{\circ} \mathrm{C}$ and high humidity up to $96.1 \%$ with light varying equal to 0 characterized by the existence of moss plants. And the temperature for the outside of the cave is $28^{\circ} \mathrm{C}$, with a humidity of $94.8 \%$ and the maximum light varying 127 lux. And the results of the analysis of the mineral content of cave ornaments with the method X-Ray Diffraction (XRD) namely a sample stalactites, stalagmite, lime in caves and outer limestone caves containing calcite $(\mathrm{CaCO} 3)$ of $100 \%$, the dominant sand containing $\mathrm{SiO} 2$ of $93 \%$ and land Contains $\mathrm{SiO} 2$ of $47 \%$.
\end{abstract}

Keywords : Cave Characteristics, Cave Ornaments, Mineral Facies, X-Ray Diffraction (XRD).

\begin{abstract}
Abstrak. Analisis Mineral Pembentuk Facies Gua Salukang Kallang Kawasan Karst Taman Nasional Bantimurung Bulusaraung Maros. Telah dilakukan penelitian dengan tujuan untuk mendeskripsikan karakteristik Gua Salukang Kallang dan menganalisis kandungan mineral facies gua. Sampel ornamen gua yang diambil adalah stalaktit, stalakmit, kapur, pasir dan tanah yang dilakukan di Laboratorium Mikrostruktur FMIPA UNM dengan menggunakan Metode X-Ray Diffraction (XRD). Dari hasil penelitian yang didapatkan dimana karakteristik Gua Salukang Kallang dapat ditemui flora, fauna, dan merupakan gua yang masih aktif ditandai dengan adanya rembesan air pada ornamen gua. Keberadaan sungai bawah tanah yang memiliki suhu rendah yaitu $26^{\circ} \mathrm{C}$ serta kelembaban tinggi hingga $96,1 \%$ dengan intesitas cahaya sama dengan nol yang ditandai dengan keberadaan tumbuhan lumut. Suhu untuk luar gua sebesar $28^{\circ} \mathrm{C}$, dengan kelembaban sebesar 94,8\% dan intesitas cahaya sebesar 127 lux. Dan hasil dari analisis kandungan mineral ornamen gua yaitu sampel stalaktit, stalakmit, kapur dalam gua dan kapur luar gua yang mengandung calcite $\left(\mathrm{CaCO}_{3}\right)$ sebesar $100 \%$, pasir dominan mengandung $\mathrm{SiO}_{2}$ sebesar 93\% dan tanah mengandung $\mathrm{SiO}_{2}$ sebesar $47 \%$.
\end{abstract}

Kata kunci : Karakteristik Gua, Ornamen Gua, Mineral Facies, X-Ray Diffraction (XRD).

\section{PENDAHULUAN}

Indonesia merupakan negara yang memiliki pegunungan karst cukup luas, membentang sepanjang Pulau Jawa dan pulaupulau lainnya. Pegunungan karst terdapat diseluruh wilayah kepulauan indonesia dengan luas kurang lebih 15,4 juta hektar. Beberapa kawasan karst yang terkenal di Indonesia yaitu kawasan karst Gunung Sewu (DIY, Jateng, Jatim), Karst Gombang (Jateng), Karst Maros-Pangkep (Sulsel), Karst Sangkulirang-Mangkaliat (Kaltim), dan kawasan Karst Gunung Lorentz 
(Papua). Kawasan Karst Maros- Pangkep di Sulawesi Selatan merupakan salah satu kawasan karst yang mempunyai bentang alam unik dan khas yang biasa disebut tower karst. Kawasan ini terletak di Kabupaten Maros tepatnya di sebelah utara Kota Makassar. Kabupaten Maros hanya berjarak sekitar $30 \mathrm{~km}$ atau sekitar 45 menit perjalanan dari Kota Makassar sehingga dapat berfungsi sebagai penyangga Kota Makassar. Jajaran karst Maros terlihat jelas dari jalan transSulawesi yang menghubungkan antara Kota Makassar dan Kota Pare-pare (Kurniawan, 2009).

Menurut Nur (2004), Kawasan Karst Maros mempunyai 268 buah gua yang tersebar di area hutan lindung Pattunuang dan Karaengta Kabupaten Maros, diantaranya 18 dengan artefak. Menurut Daryanto dan Oktariadi (2009), Enam gua yang mempunyai sistem mata air yang saling berkaitan salah satu diantaranya adalah Gua Salukang Kallang. Keadaan facies Gua Salulakang Kallang dapat dilihat dari karakteristik gua yaitu bentuk tubuh batuan yang dikombinasikan dari litlogi, struktur fisik, dan biologi yang merupakan aspek pembeda dari tubuh batuan atas, di bawah, di dalam gua, ataupun di samping gua. Gua Salukang Kallang juga memiliki banyak potensi seperti flora dan faunanya, serta stalaktit, stalakmit, dan oranamen gua yang indah.

Salukang kallang merupakan gua yang memiliki panjang kurang lebih 12,000 m. Gua ini tepatnya berada di Desa Kappang Kabupaten Maros Sulawesi Selatan. Sistem gua memiliki 8 pintu masuk. Salah satu pintu masuk gua Salukang Kallang yang arahnya vertikal dengan kedalaman kurang lebih $150 \mathrm{~m}$. Salukang kallang dengan sistem sungai bawah tanahnya, menghasilkan ornamen yang sangat menakjubkan dan sangat baik untuk mempelajari tentang hidrologi gua. Gua Salukang Kallang merupakan Gua horizontal dengan panjang lebih kurang 27 kilometer, ini menjadikan Salukang Kallang sebagai gua terpanjang di Indonesia. Gua ini termasuk dalam kawasan Taman Nasional BantimurungBulusaraung yang dikelolah dan dilindungi pemerintah. Sistem air Salukang Kallang dikenal dengan nama Sistem Towakala. Ia bermula dari Sungai Gallang, menuju Sungai Kallang, lalu Gua VCM, mengalir ke Gua Salukang Kallang, ke Gua Lubang Kabut, Lubang Batu Neraka, Gua Tanete, Wattanang, hingga Bantimurung. Dalam kondisi normal, debit air dari sistem ini mencapai 500 liter per detik. Aliran sungai bawah tanah yang terdapat di gua Sallukang Kallang merupakan sumber air utama yang biasa digunakan sebagai konsumsi. Baik oleh masyarakat Maros ataupun pemerintah kabupaten Maros melalui PDAM Tirta Bantimurung. Keberadaan sungai bawah tanah tersebut patut dijaga kelestariannya. Tidak hanya sistem perguaannya, namun juga vegetasi diatas sistem perguaan tersebut. Dengan adanya vegetasi yang bagus maka sistem tata air perguaanpun teratur dengan sendirinya.

Sejalan dengan itu, Sukmawati (2015) melakukan penelitian mengenai karakterisasi jenis mineral oranamen gua Salukang Kallang, yang merupakan salah satu gua yang terdapat di daerah Kawasan Karst Maros. Hasil yang diperoleh stalaktit, stalagmit, pilar maupun flowstone didominasi oleh warna putih kecoklatan dan mengandung calcite $\left(\mathrm{CaCO}_{3}\right)$ hingga $99 \%$, dari hasil tersebut menandakan bahwa oranamen gua Salukang Kallang masih tergolong muda dan masih bersifat aktif. Dari hasil penelitian yang di peroleh dimana Gua Salukang Kallang memiliki karakteristik yang menakjubkan dapat dilihat dari sungai bawah tanah, stalaktit, stalakmit, pilar, flowstone, kapur, tanah serta flora dan fauna yang terdapat diluar dan dalam gua. Gua Salukang Kallang dikatakan gua yang masih bersifat aktif dapat ditandai dengan adanya rembesan air pada ornamen gua dan keberadaan sungai bawah tanah yang memiliki suhu rendah yaitu $26^{\circ} \mathrm{C}$, serta kelembaban tinggi sebesar $96,1 \%$ dengan 
intensitas cahaya sama dengan 0 , yang di tandai dengan keberadaan tumbuhan lumut. Hasil analisis kandungan mineral ornamen Gua Salukang Kallang di peroleh stalakmit, stalaktit, kapur luar dan dalam gua di dominasi oleh calcite sebesar $100 \%$.

Berdasarkan latar belakang di atas maka penulis merasa perlu melakukan penelitian mengenai "Analisis Mineral Pembentuk Facies Gua Salukang Kallang Kawasan Karst Taman Nasional Bantimurung Bulusaraung Maros". Rumusan masalah dalam penelitian ini ialah "Bagaimana karakteristik Gua Salukang Kallang Kawasan Karst Taman Nasional Bantimurung Bulusaraung Maros?" dan "Bagaimana kandungan mineral ornamen Gua Salukang Kallang Kawasan Karst Taman Nasional Bantimurung Bulusaraung Maros?". Berdasarkan uraian di atas maka tujuan yang ingin dicapai dalam penelitian ini ialah untuk mendeskripsikan karakteristik Gua Salukang Kallang Kawasan Karst Taman Nasional Bantimurung Bulusaraung Maros dan untuk menganalisis kandungan mineral ornamen Gua Salukang Kallang Kawasan Kart Taman Nasional Bantimurung Bulusaraung.

\section{METODE}

Penelitian ini merupakan penelitian yang bersifat deskriptif. Penelitian deskriptif yaitu memberikan fakta tentang keadaan yang di peroleh dari hasil survei, meliputi pengamatan, pengukuran serta pencatatan data di lapangan.

Lokasi pengambilan sampel ornamen gua dan pengamatan karakteristik gua dilakukan di Gua Salukkang Kallang Desa Samangki Kecamatan Simbang Kabupaten Maros. Pengambilan sampel dilakukan di dalam dan di luar gua. Pengambilan sampel di dalam gua memliki 4 titik dari mulut gua dengan jarak yang dapat terukur dan di jangkau yaitu 200 meter, 400 meter, dan 580 meter. Dan pada bagian luar gua memiliki 3 titik dari mulut gua dengan jarak yaitu
200 meter arah kanan mulut gua dan 200 meter arah kiri mulut gua.

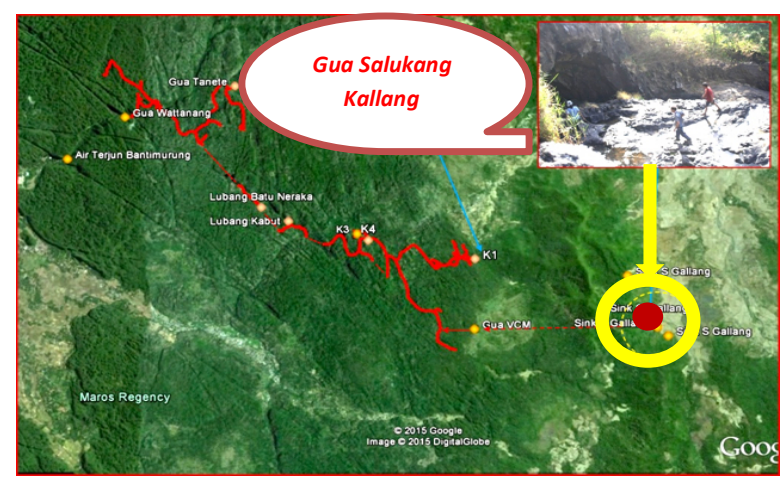

Gambar 1 Lokasi Penelitian

Beberapa alat dan bahan yang digunakan dalam penelitian ini antara lain Hygrometer, Luxmeter, roll meter, handlamp, palu, Aquades, mortar, XRD (X-Ray Diffraction), dan sampel ornamen Gua Salukang Kallang. Langkah kerja dalam penelitian ini antara lain sebagai beriku :

1. Pengukuran karakteristik Gua Salukang Kallang

a. Pengukuran temperatur Gua Salukang Kallang

b. Pengukuran intensitas cahaya

c. Pengukuran Kelembaban Gua Salukang Kallang.

2. Pengambilan sampel ornamen gua

3. Pemilihn sampel

4. Preparasi sampel

5. Karakterisasi sampel ornamen gua

6. Interpretasi data

\section{HASIL DAN PEMBAHASAN}

Adapun data hasil penelitian karakteristik gua yang diperoleh dari Gua Salukang Kallang Kawasan Karst Taman Nasional Bantimurung Bulusaraung Maros dan hasil analisis sampel ornamen gua dengan menggunakan XRD (X-Ray Diffraction).

1. Karakteristik Gua Salukang Kallang Kawasan Karst Maros

Kabupaten Maros, Kecamatan Seimbang, tepatnya di Desa Samangki terdapat Gua Salukang Kallang, dimana mulut gua Salukang 
Kallang berada di Desa Labuaja Kecamatan Canrana. Di mana mulut gua memiliki tinggi $50 \mathrm{~cm}$ dan panjang gua yang dapat di jangkau sekitar $580 \mathrm{~m}$.

Berdasarkan hasil yang dilakukan pada saat penelitian tanggal 15 Desember $2018 \mathrm{di}$ wilayah Gua Salukang Kallang diperoleh intensitas cahaya sebesar 127 lux untuk luar gua dan 0 lux di dalam gua, dengan kelembaban di dalam gua sebesar 96,1\% dan di luar gua sebesar $94,8 \%$ dan suhu di dalam gua sebesar $26^{\circ} \mathrm{C}$ dan bagian luar gua sebesar $28^{\circ} \mathrm{C}$. dengan jarak masing-masing 200 meter dari arah mulut gua.

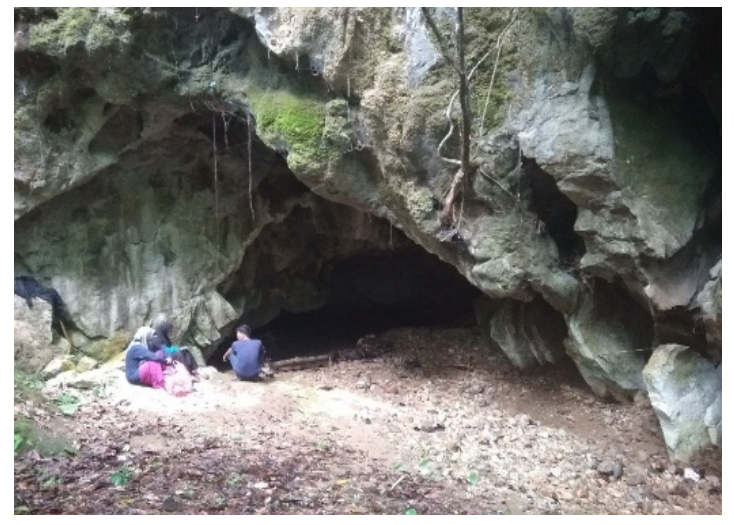

Gambar 2 Mulut Gua Salukang Kallang

(Foto Rati Puspita Sari, 2018)

Dari hasil pengamatan di lapangan karakteristik Gua Salukang Kallang Kawasan Karst Maros dapat dilihat dari sungai bawah permukaa, flora gua, fauna gua dan ornamen gua.

a. Sungai Bawah Permukaan Gua

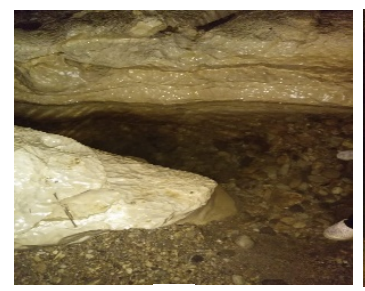

(a)

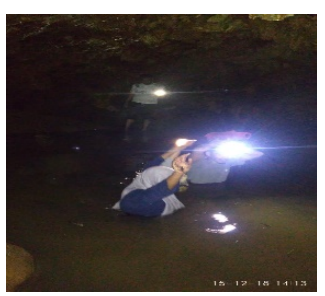

(b)
Gambar 3. (a). Sungai bawah tanah berupa aliran dan (b) sungai bawah tanah berupa aliran. (Foto Rati Puspita Sari, 2018).

Didalam Gua Salukang Kallang terdapat genangan air dan aliran air yang menandakan adanya sungai bawah permukaan dan merupakan gua yang masih aktif. Air yang jatuh kebawa permukaan tanah akan terakumulasi dalam satu pola aliran kemudian membentuk aliran sungai bawah tanah, selain itu sebagian aliran juga berasal dari sungai luar gua yang mengalir masuk kedalam gua saat musim hujan kemudian tergenang di dalam gua, sehingga mineral yang terkandung pada ornamen gua salukang kallang di dominasi oleh Calcite $\left(\mathrm{CaCO}_{3}\right)$ hingga $100 \%$.

\section{b. Flora Gua Salukang Kallang}

Di Gua Salukang Kallang terdapat tumbuhan lumut yang hidup di sekitar/di luar gua dan berbagai jenis tumbuhan seperti yang sering hidup di dalam gua yang jarang di temukan.

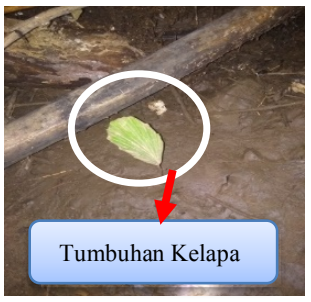

(a)

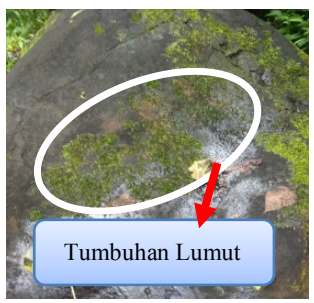

(c)

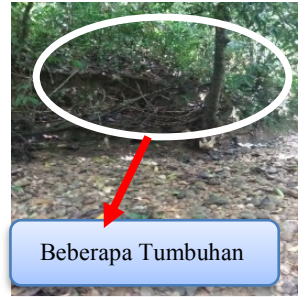

(b)

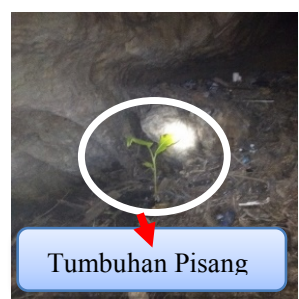

(d)
Gambar 4. Jenis Tumbuhan yang Berada Di Luar Gua. (a) tumbuhan kelapa yang terdapat di sekitar dalam mulut gua, (b) beberapa tumbuhan yang terdapat diluar gua, (c) tumbuhan lumut yang terdapat di batuan, dan (d) tumbuhan pisang terdapat di sekitar dalam mulut gua. (Foto Rati Puspita Sari, 2018)

\section{c. Fauna Gua Salukang Kallang}


Adapun fauna yang terdapat di dalam Gua Salukang Kallang seperti labalaba, jangkrik, ikan lele dan kelelawar.

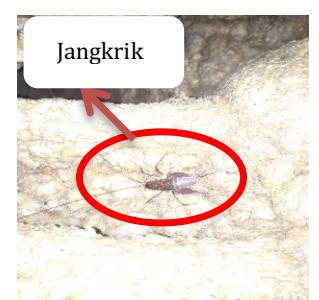

(a)

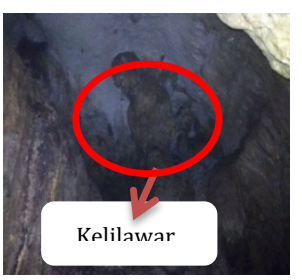

(c)

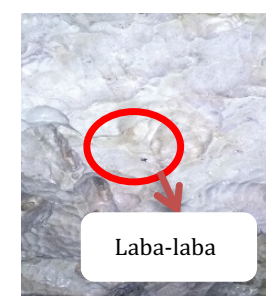

(b)

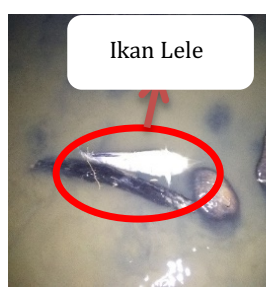

(d)
Gambar 5. Fauna Gua Salukang Kallang (a) Jangkrik, (b) Laba-laba, (c) Kelilawar, (d) Ikan Lele (Foto Rati Puspita Sari, 2018).

Fauna yang terdapat Gua Salukang Kallang ada dapat bertahan hidup da nada juga yang tidak dapat bertahan hidup. Adapun Fauna yang ada di dalam gua tidak dapat bertahan hidup disebabkan karena keadaan tertentu seperti terbawa banjir

\section{d. Ornamen Gua Salukang Kallang}

Beberapa ornamen gua yang dapat ditemukan di dalam gua, diantaranya yaitu stalaktit, stalakmit, flowstone, pilar.

Stalaktit terbentuk karena pengendapan mineral di atap gua. Air yang mengandung kalsium karbonat muncul di atap gua kemudian menggantung sebelum jatuh ke lantai gua. Selama menggantung tersebut, $\mathrm{CO}_{2}$ menguap ke atmosfer gua, larutannya menjadi sangat jenuh air dan bahan mineralnya yang sangat sedikit jumlahnya akan tertinggal melingkar dengan ukuran sama dengan tetesannya. Stalakmit merupakan sebagian tetesan air yang berasal dari atap gua menetes sampai ke lantai dan meninggalkan senyawa kalsium karbonat dalam bentuk stalagmit. Tetesan yang jatuh ke bawah lantai gua terus mengendapkan material dan membangun suatu gundukan ornament. Flowstone merupakan bentuk ornamen gua yang terbentuk dari milyaran tetesan air disebabkan oleh aliran air dan menyelubungi bongkahan batu. Pilar merupakan jenis ornamen yang terbentuk apabila stalaktit dan stalakmit bertemu. Ornamen ini memiliki bentuk menyerupai tiang yang menyangga di atap gua dengan ukuran yang bervariasi

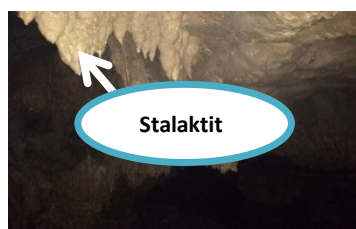

(a)

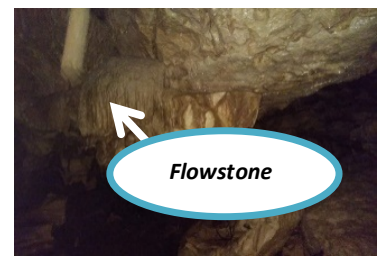

(c)

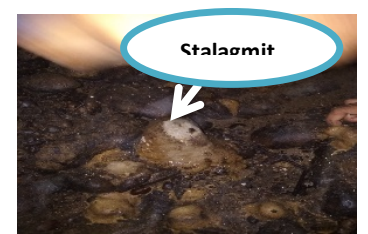

(b)

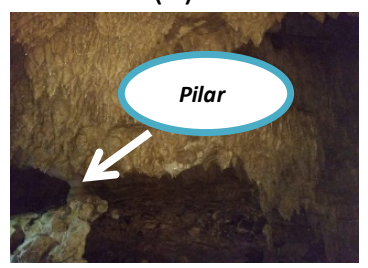

(d)
Gambar 6. Ornamen Gua Salukang Kallang (a) Stalaktit, (b) Stalakmit, (c) flowstone, (d) pilar (Foto Rati Puspita Sari, 2018).

\section{Karakteristik Ornamen Gua Salukang Kallang} Kawasan Maros Karst

Dari hasil pengamatan di lapangan terdapat beberpa ornament di dalam Gua Salukang Kallang Kawasan Karst Maros yaitu stalaktit, stalakmit, pilar dan flowstone. 
Tabel 1. Karakteristik Bagian Luar Gua Salukang Kallang

\begin{tabular}{cccc}
\hline Dimensi Gua (meter) & Kelembaban (\%) & Suhu $\left({ }^{\circ} \mathbf{C}\right)$ & $\begin{array}{c}\text { Intensitas Cahaya } \\
\text { (Lux) }\end{array}$ \\
\hline 0 & 92,1 & 28 & 127 \\
200 & 94,3 & 27 & 118 \\
200 & 94,8 & 26 & 112 \\
\hline
\end{tabular}

Tabel 1 merupakan karakteristik ornamen gua yang meliputi bagian luar gua, dimana pada bagian kiri dan kanan dengan jarak masing- masing 200 meter dari mulut gua yang memiliki perbedaan kelembaban, suhu, dan intensitas cahaya.

Tabel 2. Karakteristik Bagian Dalam Gua Salukang Kallang

\begin{tabular}{cccc}
\hline Dimensi Gua (meter) & Kelembaban $(\%)$ & Suhu $\left({ }^{\circ} \mathbf{C}\right)$ & $\begin{array}{c}\text { Warna Oranmen } \\
\text { Gua }\end{array}$ \\
\hline 200 & 96,1 & 26 & Putih kecoklatan \\
400 & 94,8 & 26 & $\begin{array}{c}\text { Putih kekuningan } \\
\text { Putih coklat } \\
\text { kekuningan }\end{array}$ \\
\hline
\end{tabular}

Tabel 2. merupakan karakteristik ornamen gua yaitu stalaktit, stalagmit, flowstone, dan pilar pada jarak tertentu, dimana pada setiap stalaktit, stalakmit, flowstone, dan pilar tersebut memkiliki perbedaan warna dengan jarak tertentu dari setiap sampel yang tidak terlalu mencolok yaitu di dominasi oleh warna putih coklat kekuningan.

3. Karakteristik Jenis Mineral Ornamen Gua Salukang Kallang Kawasan Maros Karst

Karakterisasi menggunakan X-Ray Diffraction (XRD) dilakukan untuk mengetahui jenis mineral setiap sampel ornamen gua yang meliputi stalaktit, stalagmit, pilar dan flowstone. Adapun hasil dari karakterisasi tersebut yaitu seperti berikut ini.

Pada Tabel 3 dapat dilihat komposisi fase sampel ornamen gua Salukang Kallang, dimana sampel stalaktit, stalakmit, kapur dalam dan luar gua memiliki persentase calcite $100 \%$, dan pada sampel lain memiliki kandungan dan persentase yang berbeda-beda.

Tabel 3. Komposisi fase mineral sampel ornament gua dengan metode XRD

\begin{tabular}{|c|c|c|c|}
\hline No. & Nama Sampel & Komposisi Fase & Presentase $(100 \%)$ \\
\hline 1 & Stalaktit & Calcite & $100 \%$ \\
\hline 2 & Stalagmit & Calcite & $100 \%$ \\
\hline 3 & Kapur Dalam Gua & Calcite & $100 \%$ \\
\hline \multirow[t]{2}{*}{4} & Pasir Dalam Gua & $\begin{array}{l}\text { quartz low HP, } \\
\text { alpha-SiO }\end{array}$ & $70 \%$ \\
\hline & & Corundum, syn & $30 \%$ \\
\hline 5 & Tanah Luar Gua & Calcium Peroxide & $5,2 \%$ \\
\hline
\end{tabular}


Jurnal Sains dan Pendidikan Fisika (JSPF)

Jilid 15, Nomor 3. Desember 2019

Hal: $78-85$

Hasil karakterisasi X-Ray Diffraction (XRD) diperoleh informasi bahwa keseluruhan sampel ornamen Gua Salukang Kallang dari jarak 200 meter, 400 meter, hingga 580 meter dari mulut gua yang dapat di ukur memiliki kesamaan baik stalaktit, stalagmit, kapur, pasir, dan tanah yaitu mengandung jenis mineral calcite $\left(\mathrm{CaCO}_{3}\right)$ sebagai komposisi utama hingga $100 \%$ dan beberapa sampel tersebut memiliki komposisi yang sama yaitu quartz $\left(\mathrm{SiO}_{2}\right)$, corundum, calcium peroxide, dan hypothetical silica. Sedangkan menurut hasil penelitian dari Sukmawati, (2015) di peroleh persentase mineral dari Gua Salukakang yaitu pada sampel stalaktit, stalakmit, pilar, dan flowstone didominasi calcite hingga 99\% dan beberapa persen quartz $\mathrm{SiO}_{2}$ yang merupakan pengotor. Dari hasil penelitian yang telah dilakukan dapat dilihat bahwa adanya kesamaan pada penelitian Sukmawati (2015) dimana kandungan mineral gua salukang kallang masih di dominasi oleh calcite yang mencapai $100 \%$ untuk sampel stalaktit dan stalakmit. Adanya perbedaan dalam penelitian Sukamawati (2015), dimana pengambilan sampel yang diteliti yaitu stalaktit, stalakmit, pilar dan flowstone sedangkan pada penelitian ini dilakukan pemengambilan sampel stalaktit, stalakmit, kapur, pasir dan tanah, sehingga mineral yang terkandung dari beberapa sampel yang di teliti memiliki kandungan yang berbeda-beda.

Dari hasil analisis sampel Gua Salukang Kallang dengan hasil analisis sampel yang diperoleh oleh Risqah (2013) dimana pada hasil penelitian analisis sampel Gua Mimpi Bantimurung terlihat berbeda dengan hasil analisis sampel Gua Salukang Kallang, hal ini

\section{DAFTAR RUJUKAN}

Arsyad, M. Nasrul Ihsan, Vistarani Arini Tiwow, 2015. Estimation of Underground River Water Availability Based Rain Fall in The Maros Karst Region South Sulawesi
ISSN Cetak: 1858-330X dan

ISSN Online: 2548-6373

dikarenakan Website:http://ois.unm.ac.id $\begin{gathered}\text { ornamen-ornamen } \\ \text { Orampi }\end{gathered}$ Bantimurung sudah berusia tua, ini dapat dilihat dari ukuran ornamen seperti stalaktit yang mencapai hingga $190 \mathrm{~cm}$, sedangkan ornamenornamen yang ditemukan di Gua Salukang Kallang masih berusia sangat muda dapat dilihat dari ornamen-ornamen gua yang masih bersifat sangat aktif ditandai dengan terdapatnya rembesan air pada ornamen tersebut.

\section{SIMPULAN}

Karakteristik Gua Salukang Kallang Kawasan Karst Maros meliputi sungai temperatur, intensitas cahaya, kelembaban, flora dan fauna gua serta keberadaan ornamen gua. Beberapa jenis fauna yang ditemukan di dalam gua yakni kelelawar, belalang, laba-laba, jangkrik, dan ikan lele. Sedangkan flora yang ditemukan yaitu berupa tumbuhan lumut, keberadaannya menandakan didalam gua tersebut memiliki intensitas cahaya dan temperatur rendah, serta kelembaban yang tinggi. Beberapa ornamen gua yang dapat diliha seperti stalaktit, stalakmit, pilar, flowstone, kapur, dan pasir dan Jenis kandungan mineral facies ornamen gua seperti stalaktit, stalakmit, kapur dalam gua, dan kapur luar gua memiliki kesamaan yakni didominasi oleh calcite $\left(\mathrm{CaCO}_{3}\right)$ hingga $100 \%$ dan pada sampel pasir dalam gua, tanah luar gua, pasir dalam gua, dan pasir luar gua, mengandung mineral facies gua yaitu quartz (alpha-SiO$)_{2}$ ) mulai dari 47,9 \% hingga $93 \%$, dan ada pula yang memiliki kandungan mineral corundum $30 \%$, calcium peroxide $5,2 \%$ dan hypothetical silica $7 \%$ yang merupakan pengotor.

(MSCEEIS FMIPA UPI Bandung, Oktober 2015)

Arsyad, M. 2016. Ilmu Kebumian. Makassar: Badan Penerbit Universitas Negeri Makassar 
Boggs Jr, Sam., 1987, Principles of Sedimentology and Stratigraphy 3rd Edition. Prentice Hall.

Daryanto, A. dan Oktariadi. 2009. Klasifikasi Kawasan Karst Maros Sulawesi Selatan untuk Menentukan Kawasan Lindung dan Budidaya. Majalah Pusat Lingkungan Geologi, 19(2): 67-81.

Hibbard, M.J. 2002. Mineralogy: A Geologist's Point Of View. McGraw-Hill, Boston. $562 \mathrm{~h}$.

Kurniawan, R., Eriyatno., Rukman, S. dan Alinda. (2009). Valuasi Ekonomi Jasa Lingkungan Kawasan Karst MarosPangkep. Jurnal Ekonomi Lingkungan. 13(1) : 51-60.

Mutti, E. \& Ricci Lucci, F. (1972), Le torbidity dell apenino settentrionale: introduzione all'analisi di facies: memorie della Societa Geologia Italiana, v.11, p. 161 - 199. English
Translation by T.H. Nilsen, 1978, International Geology Review, v. 20, p. 125-166.

Nur. 2004. Tim Ekspedisi Gua-Gua Karst Maros: Makassar.

Rizqah. (2013) Studi Tentang Struktur Dan Komposisi Mineral Ornamen Gua Kawasan Karst Maros. Makassar: Jurusan Fisika Fakultas MIPA UNM.

Sukmawati, Pariabti Palloan, Muhammad Arsyad 2015. Karakterisasi Jenis Mineral Ornamen Gua Salukang Kallang Dengan Metode X-Ray Diffraction. Jurnal Sains Dan Pendidikan Fisika, Jilid 11 Nomor 3.

Wiharto, M. 1998. Struktur, Komposisi, dan Produktivitas Vegetasi di Cagar Alam Karengta Kbupaten Maros Sulawesi Selatan. Thesis S2. Program Pascasarjana Universitas Gajah Mada : Yogyakarta. 